\title{
Heat Strain in Cold
}

\section{Hannu RINTAMÄKI* and Sirkka RISSANEN}

Finnish Institute of Occupational Health Oulu, Aapistie 1, FI-90220 Oulu, Finland

Received February 28, 2006 and accepted April 11, 2006

\begin{abstract}
In spite of increased environmental cold stress, heat strain is possible also in a cold environment. The body heat balance depends on three factors: environmental thermal conditions, metabolic heat production and thermal insulation of clothing and other protective garments. As physical exercise may increase metabolic heat production from rest values by ten times or even more, the required thermal insulation of clothing may vary accordingly. However, in most outdoor work, and often in indoor cold work, too, the thermal insulation of clothing is impractical, difficult or impossible to adjust according to the changes in physical activity. This is especially true with whole body covering garments like chemical protective clothing. As a result of this imbalance, heat strain may develop. In cold all the signs of heat strain (core temperature above $38^{\circ} \mathrm{C}$, warm or hot thermal sensations, increased cutaneous circulation and sweating) may not be present at the same time. Heat strain in cold may be whole body heat strain or related only to torso or core temperature. Together with heat strain in torso or body core, there can be at the same time even cold strain in peripheral parts and/or superficial layers of the body. In cold environment both the preservation of insulation and facilitation of heat loss are important. Development of clothing design is still needed to allow easy adjustments of thermal insulation.
\end{abstract}

Key words: Cold exposure, Exercise, Heat production, Thermal insulation, Clothing, Protective garment

\section{Introduction}

Heat strain in cold conditions is a common phenomenon and depends usually on the difficulty or inability to change the clothing insulation according to the needs of chanced heat production ${ }^{1-5)}$. Anecdotal stories tell even about heat exhaustion during military exercises in cold, when maximal amount of clothing is worn and exercise intensity has increased to high levels. However, published results on heat strain in cold are rare.

Heat strain in cold is equally hazardous as in warm environment, although all the signs of heat strain (warm or hot thermal sensations, discomfort, sweating, high core and/ or skin temperatures, increased cardiac work) may not be present at the same time. The additional feature in heat strain in cold is that during the periods of heat strain, sweating will be accumulated in clothing which impairs the thermal insulation and increases the risk of cold strain in subsequent phases of work with lower heat production.

*To whom correspondence should be addressed.
This paper focuses on heat balance in cold, with observations on heat strain in outdoor and indoor cold exposures, and observations from exercise with whole body covering chemical protective garments in cold.

\section{Heat Balance in Cold}

In a given ambient thermal condition, body heat balance depends on metabolic heat production and heat loss/gain by radiation, conduction, convection and evaporation. The thermal insulation of the clothing is in the main role in adjusting different forms of heat loss. Metabolic heat production is composed of basal metabolism and regulated heat production. Basal metabolic rate can be changed very little, mainly by thyroid hormones. Eating can increase heat production by $15 \%$ for a couple of hours. The main source of variation in metabolic heat production is the variation in muscular work either by physical activity or cooling induced shivering. Basal metabolic rate (BMR) is ca. $58 \mathrm{~W} / \mathrm{m}^{2}$, 
and physical exercise can increase metabolic rate, depending on individual's physical fitness, maximally 10-13 times BMR, while shivering can increase the metabolic rate ca. 3 times BMR. Almost the whole metabolic rate is converted to heat while resting and shivering. During physical exercise the proportion of external work is ca. 0-20\% from metabolic rate, leaving $80-100 \%$ of metabolic rate to be converted to heat ${ }^{6}$.

If the ambient thermal conditions are stable, the variation in metabolic heat production is the main factor causing imbalance in body heat balance. There can be at least two reasons for this imbalance: level of physical work may vary largely during the work and pauses, or the clothing may be worn for the initial conditions with low heat production and later on, when exercise starts to produce heat, the thermal insulation of the clothing is exaggerated.

Both whole body heat balance and local protection against cooling should be taken care in the cold. Even with torso heat strain it is usually not practical to uncover large areas of body to facilitate heat loss, as unprotected areas may suffer from a local cold strain. Therefore, a certain level of whole body thermal protection should be maintained in most conditions.

Usually the thermal insulation of work clothing in cold environment is around 2 clo. Such kind of clothing could be composed, e.g., from underwear with short sleeves and legs, shirt, trousers, jacket, heavy quilted outer jacket and overalls, socks, shoes, cap, gloves ${ }^{6}$. It may also be consisted of protective components, like helmet, safety boots and special gloves, against non-thermal hazards, which also increase the thermal insulation. Figure 1 shows the thermal insulation required for maintaining good heat balance at different levels of physical work at ambient temperatures between -50 and $+10^{\circ} \mathrm{C}^{7,8}$. The figure shows, that with a 2.0 clo clothing the risk for accumulation of heat starts above $+4^{\circ} \mathrm{C}$ with low level of work, above $-13^{\circ} \mathrm{C}$ with moderate work, above $-32^{\circ} \mathrm{C}$ with high level of work and above -49 ${ }^{\circ} \mathrm{C}$ with very high level of work. The figure shows also the risk limits of starting of heat accumulation for 1.5 clo clothing, which could be consisted of, for example, underwear with short sleeves and legs, shirt, trousers, jacket, thermojacket and trousers, socks and shoes ${ }^{6)}$.

\section{Experiences from Field and Laboratory}

Budd ${ }^{2}$ studied the members of the International Biomedical Expedition to the Antarctic. He recorded their thermal comfort, clothing, and activity for $60 \mathrm{~d}$ while travelling by motor toboggan and living in tents on the Antarctic plateau. Air temperature averaged $-14^{\circ} \mathrm{C}$ (range

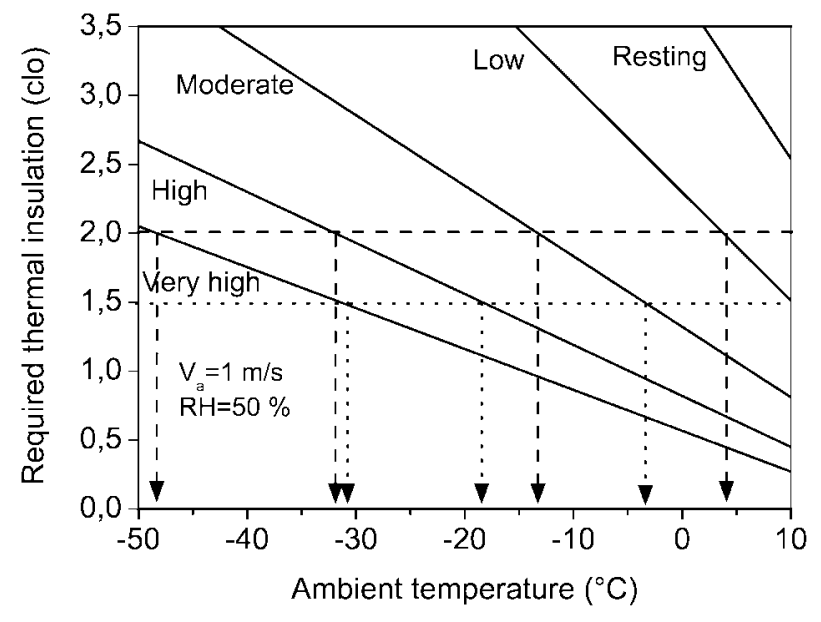

Fig. 1. Required thermal insulation of the clothing calculated for different ambient temperatures and work levels: resting (65 W/ $\left.\mathrm{m}^{2}\right)$, low $\left(100 \mathrm{~W} / \mathrm{m}^{2}\right)$, moderate $\left(165 \mathrm{~W} / \mathrm{m}^{2}\right)$, high $\left(230 \mathrm{~W} / \mathrm{m}^{2}\right)$ and very high $\left(290 \mathrm{~W} / \mathrm{m}^{2}\right)$.

External work has been assumed to be $0 \%$ at the two lowest activity levels and $5 \%$ at the other levels of exercise. Air velocity is $1 \mathrm{~m} / \mathrm{s}$ and relative humidity $50 \%$. The arrows point the ambient temperature, above which heat load is possible to develop with a given thermal insulation $^{7,8)}$ of 2.0 clo (dashed line) and 1.5 clo (dotted line).

+2 to $-29^{\circ} \mathrm{C}$ ) and wind speed $11 \mathrm{~m} / \mathrm{s}$ (range 0 to $22 \mathrm{~m} / \mathrm{s}$ ). Men were outdoors for $7.6 \mathrm{~h}$ of the $12 \mathrm{~h}$ sampling period on travel days and for $3.6 \mathrm{~h}$ on camp days. Bulky down-filled clothing, typical of that used by present-day polar expeditions, adequately protected the trunk from cold at the cost of overheating during exercise. Face, hands, and feet were less well protected, and they experienced cold-induced numbness and pain in $33 \%, 19 \%$, and $12 \%$, respectively, of the observations made in the coldest weather. Because men could not conveniently reduce clothing insulation to the extent required, sweating and discomfort from warmth increased with energy expenditure and were present in $60 \%$ of the observations made during heavy work.

In military field training body heat balance was studied in 64 conditions at ambient temperatures between 0 and $29^{\circ} \mathrm{C}$, and the duration of the training sessions varied from $55 \mathrm{~min}$ to $9.5 \mathrm{~h}^{9,10)}$. The results showed that marked cold strain (mean skin temperature $\left(\mathrm{T}_{\mathrm{sk}}\right)<27^{\circ} \mathrm{C} /$ thermal sensation "cold-very cold") was common over the whole ambient temperature range. A common reason for cooling was low physical activity. However, cold strain was evident only in the superficial and peripheral parts of the body. Rectal temperature $\left(\mathrm{T}_{\text {rect }}\right)$ was dependent on the level of physical activity, and when Trect exceeded $37.6^{\circ} \mathrm{C}$ (corresponding moderate work level) feet, hand and cheek temperatures, as well as $T_{\text {sk }}$, started to increase. That level of $T_{\text {rect }}$ corresponds 
to moderate work level (60\% of maximal metabolic rate) $)^{11)}$.

During the training sessions, where long transportations were mainly done by all-terrain vehicles, $\mathrm{T}_{\text {rect }}$ exceeded $38.0^{\circ} \mathrm{C}$ (which is regarded as a limit of heat strain ${ }^{6}$ ) for $5 \%$ of time and $37.8^{\circ} \mathrm{C}$ (associated with increased skin temperatures) for $14 \%$ of time. Thermal sensations of "slightly warm" or warmer were recorded in $17 \%$ of cases. Thermal sensations of "warm" or "hot" were recorded in $3 \%$ of cases. Different thermal sensations were recorded with lower skin temperatures than measured in laboratory, probably because of cold acclimatisation: warm thermal sensation was recorded when $\mathrm{T}_{\text {sk }}$ was $31.5^{\circ} \mathrm{C}(\mathrm{SD} 0.2)$ and hot sensation at $32.0^{\circ} \mathrm{C}(\mathrm{SD} 0.4)^{9,10)}$.

Figure 2 shows an example of long $(7.5 \mathrm{~h})$ patrol skiing at $-8^{\circ} \mathrm{C}$, where $\mathrm{T}_{\text {rect }}$ vary with levels of activity, occasionally increasing above $38.0^{\circ} \mathrm{C}$. Because physical activity was variable but almost continuous, $\mathrm{T}_{\mathrm{sk}}$ stayed on a quite high level throughout the training session ${ }^{9,10}$.

The length of the exercise bouts affects the development of heat strain as shown in $2 \mathrm{~h}$ laboratory test sessions at -15 ${ }^{\circ} \mathrm{C}$, where exercise/rest bouts lasted either for $20 \mathrm{~min}(10$ min exercise/10 min rest) or $60 \mathrm{~min}$ (30 min exercise/30 min rest). During the longer sessions $\mathrm{T}_{\text {rect }}$ increased to a considerably higher level than during the shorter sessions (Fig. 3). In both occasions, $\mathrm{T}_{\mathrm{sk}}$ decreased during the whole test period from ca. 33.0 to $30.0^{\circ} \mathrm{C}^{12,13)}$.

Sweating is evident for active individuals in the cold even though the rate of sweat production may remain $\operatorname{low}^{14-16)}$. Sweating depends both on core and skin temperatures. During exercise with core temperatures above $37.6^{\circ} \mathrm{C}$ marked sweating is possible even at low skin temperatures like 26 ${ }^{\circ} \mathrm{C}^{14)}$. Sweating has been observed during running 10-11 $\mathrm{km} / \mathrm{h}$ even when $\mathrm{T}_{\text {sk }}$ has been as low as $20^{\circ} \mathrm{C}$ (Rintamäki et al. unpublished).

\section{Chemical Protective Clothing in the Cold}

Chemical protective (CP) garment is used to protect its wearer from a contaminated environment. Low water vapour permeability and increased thermal insulation are characteristics for the most CP garments. Thus CP garment, together with the respirator and rubber gloves and boots, severely constrains body's normal heat dissipating mechanisms, most markedly the evaporation of sweat ${ }^{17,18}$. Consequently, body heat storage is increased and the user is exposed to heat stress conditions which may lead to inability to continue the performance ${ }^{19)}$. The weight and bulk of encapsulating overgarments as well as the loose fit increase energy requirements for most tasks ${ }^{20,21)}$. Energy

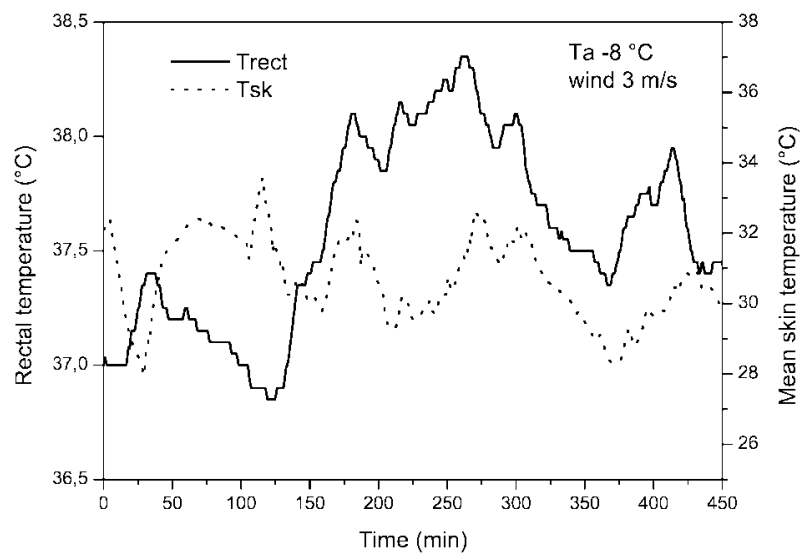

Fig. 2. Rectal and skin temperatures during military patrol skiing with variable work levels ${ }^{9,10}$.

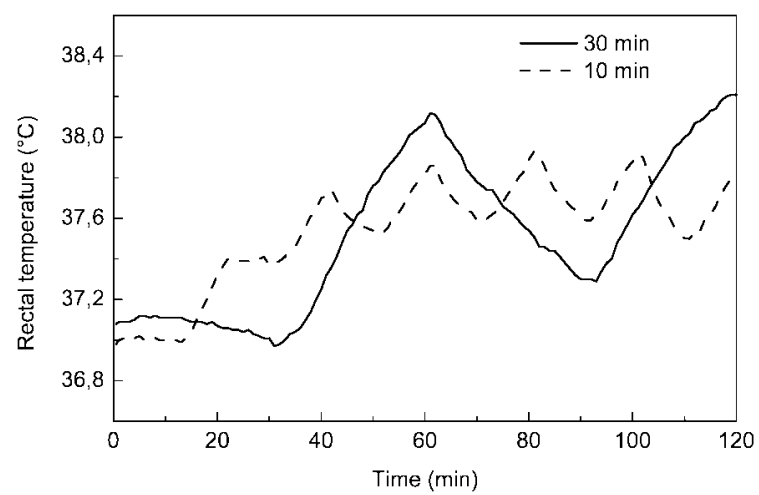

Fig. 3. The effect of the length of the exercise bouts on rectal temperature.

Exercise/rest bouts lasted either for $20 \mathrm{~min}$ (10 min exercise/10 min rest) or $60 \mathrm{~min}$ (30 min exercise $/ 30 \mathrm{~min}$ rest). Exercise (walking on treadmill $6 \mathrm{~km} / \mathrm{h}$, slope $2^{\circ}$ ) was performed at $-15^{\circ} \mathrm{C}$ (air velocity $2.5 \mathrm{~m} / \mathrm{s}$ ) and rest at $10^{\circ} \mathrm{C}($ calm). During walking the subjects had a $12 \mathrm{~kg}$ rucksack. The thermal insulation of the threelayer clothing was ca. $2.0 \mathrm{clo}^{12,13)}$.

cost of walking increases about $3 \% / c$ lothing $\mathrm{kg}$, when multilayered clothing ensembles are worn ${ }^{22}$. Also, hobbling effects of the clothing ${ }^{23)}$ and increased stiffness of the overgarment due to cooling of the material ${ }^{24)}$ increase energy cost. The full-face mask furthermore decreases evaporation from skin and increases thermal and physiological strain by increasing respiratory resistance ${ }^{25)}$. The heat strain associated with wearing the $\mathrm{CP}$ garment at high ambient temperatures is well documented (e.g. ${ }^{26-28)}$ ).

The use of CP clothing is not limited only to warm or hot conditions. The preparedness to use $\mathrm{CP}$ is also required in cold environments. Additional clothing layers further 
increase the bulkiness of the protective clothing system. Adjustment of the thermal insulation of the clothing by donning or doffing clothing layers according to activity level is not possible in the contaminated area ${ }^{29}$. It has been shown that wearing $\mathrm{CP}$ protective clothing during heavy activity may cause performance decrements due to the heat strain at wide range of ambient temperature $\mathrm{s}^{30,31)}$.

The increase in $\mathrm{T}_{\text {rect }}$ is mainly dependent on the level of physical activity ${ }^{11)}$ rather than ambient temperature during physical activities. Furthermore, increase of $\mathrm{T}_{\text {rect }}$ is time dependent. During moderate to heavy work $\mathrm{T}_{\text {rect }}$ can easily exceed $38^{\circ} \mathrm{C}$ (Fig. 4) and may thus put the individual at risk of hyperthermia and heat exhaustion when the $\mathrm{CP}$ overgarment and two layers of underwear are worn even at as low as $-25--30^{\circ} \mathrm{C}$. In the cold it is typical that individuals wearing $\mathrm{CP}$ garment experience a decrease in $\mathrm{T}_{\mathrm{sk}}$, irrespective of whether they are inactive ${ }^{30)}$ or active ${ }^{16,30,32)}$ although core temperature increases and sweating occurs. In the Fig. 4 it is illustrated how $\mathrm{T}_{\mathrm{sk}}$ decreases during moderate activity level while $T_{\text {rect }}$ increases. $T_{\text {sk }}$ is also affected by the duration of the exposure to cold. In the study of Cortili et al. ${ }^{32)} \mathrm{T}_{\mathrm{sk}}$ was $26.8^{\circ} \mathrm{C}$ after 120 and 56 -min exercise at the moderate workload at the ambient temperatures of $0^{\circ} \mathrm{C}$ and $-20^{\circ} \mathrm{C}$, respectively. Decrease in $\mathrm{T}_{\mathrm{sk}}$ is mainly caused by skin cooling in peripheral parts of the body. Skin temperature at the upper body is maintained at higher level than $\mathrm{T}_{\mathrm{sk}}$.

Because the heat dissipation by evaporation is diminished due to the low moisture penetration through the clothing system, warm and humid microclimate is developed inside the clothing. Sweating is thus worsening, not relieving, the heat strain while CP clothing is worn. Sweat accumulation within clothing during work may degrade clothing insulation and disrupt thermal balance during subsequent periods of rest or low intensity activity ${ }^{30}$. Moreover, excessive cooling of fingers and hands is often resulted from poor thermal insulation of the protective glove system coupled with sweat accumulation in them ${ }^{30,33)}$.

The results of several studies ${ }^{15,24,31,32)}$ concerning heat and cold strain in the cold while wearing CP clothing is summarized in Table 1. In the table thermal strain is assessed at different activity levels and at different ambient temperatures while $\mathrm{CP}$ clothing is worn ${ }^{31)}$. The activity level is classified as light, moderate and heavy and thermal strain is classified to three categories: discomfort, performance decrement and tolerance according to Loten ${ }^{34}$. In the Table 1 heat strain is based on both $\mathrm{T}_{\text {rect }}$ and $\mathrm{T}_{\text {sk }}$. If only $\mathrm{T}_{\text {rect }}$ above $38^{\circ} \mathrm{C}$ is taken as a criterion for heat strain, risk of heat strain would be evident during heavy work or higher activity even at $-30^{\circ} \mathrm{C}$.

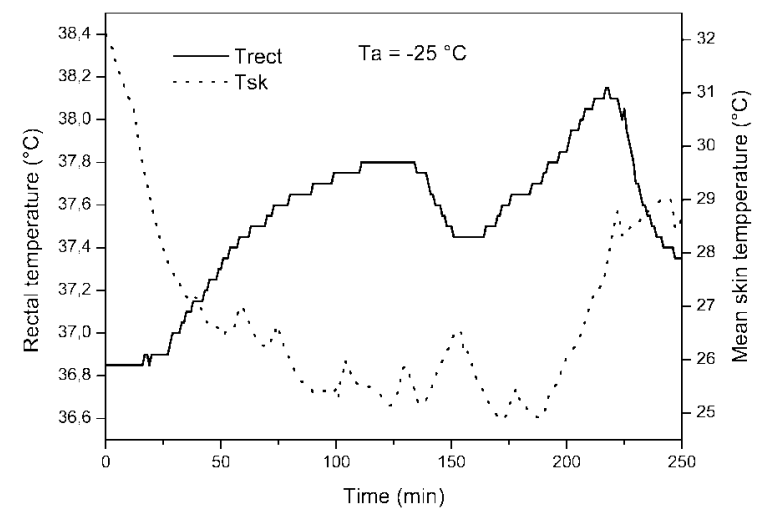

Fig. 4. Rectal and mean skin temperature during moderate (25-125 min) and heavy (150-220 min) exercise at ambient temperature of $-25^{\circ} \mathrm{C}$ while wearing chemical protective clothing ${ }^{31)}$.

\section{Conclusions}

The results from field and laboratory measurements show that heat strain is possible in cold during periods of increased physical activity, if the adjustment of clothing insulation is not possible. Moreover, there can be heat strain in torso even when there is no heat strain in peripheral parts of the body, or even when there is cold strain in the periphery. During exercise in cold with adequate clothing, skin temperatures start to increase when $\mathrm{T}_{\text {rect }}$ exceeds $37.6^{\circ} \mathrm{C}$, and there can be heat strain judged from core temperature and sweating even when skin temperatures are low. Therefore, in cold environment both the preservation of insulation and facilitation of heat loss are important. Development of clothing design is still needed to allow easy adjustments of thermal insulation according to the changes in physical activity.

\section{References}

1) Budd GM (1966) Skin temperature, thermal comfort, sweating, clothing and activity of men sledging in Antarctica. J Physiol 186, 201-15.

2) Budd GM, Hendrie AL, Jeffery SE (1986) Behavioural temperature regulation during a motor-toboggan traverse in Antarctica. Eur J Appl Physiol Occup Physiol 55, 507-16.

3) Pascoe DD, Bellingar TA, McCluskey BS (1994) Clothing and exercise. II. Influence of clothing during exercise/work in environmental extremes. Sports Med 18, 94-108.

4) Ainslie PN, Reilly T (2003) Physiology of accidental hypothermia in the mountains: a forgotten story. Br J Sports Med 37, 548-50.

5) Gavin TP (2003) Clothing and thermoregulation during exercise. Sports Med 33, 941-7. 
Table 1. Probability of heat strain or cold strain (within $60 \mathrm{~min}$ ) of wholebody and fingers as a function of physical activity level and ambient temperature, when wearing chemical protective clothing.

\begin{tabular}{|c|c|c|c|c|c|c|c|c|}
\hline \multicolumn{2}{|c|}{ Activity level } & \multicolumn{5}{|c|}{ Risk of thermal strain } & \multicolumn{2}{|r|}{ Body } \\
\hline \multirow{2}{*}{ Heavy } & $0 /-$ & $0 /-$ & 0 & 0 & + & + & + & Whole body \\
\hline & - & - & - & 0 & 0 & 0 & 0 & Fingers \\
\hline \multirow{2}{*}{ Moderate } & - & - & $0 /-$ & $0 /-$ & 0 & + & + & Whole body \\
\hline & - & - & - & - & 0 & 0 & 0 & Fingers \\
\hline \multirow{2}{*}{ Light } & - & - & - & -0 & 0 & 0 & 0 & Whole body \\
\hline & - & - & - & - & - & - & 0 & Fingers \\
\hline \multirow{3}{*}{$\begin{array}{l}\text { Very light/ } \\
\text { rest }\end{array}$} & - & - & - & - & 0 & 0 & 0 & Whole body \\
\hline & - & - & - & - & - & 0 & 0 & Fingers \\
\hline & -30 & -25 & -20 & -15 & -10 & -5 & 0 & \\
\hline \multicolumn{9}{|c|}{ Ambient temperature $\left({ }^{\circ} \mathrm{C}\right)$} \\
\hline
\end{tabular}

0 (neutral); heat strain: + (discomfort); cold strain: - (discomfort), - (performance decrement $),-(\text { tolerance })^{31)}$.

6) Parsons KC (2003) Human thermal environments. Taylor \& Francis, London.

7) ISO 11079 (1999) Ergonomics of the thermal environmentcold environments. Determination of required clothing insulation (IREQ). ISO, Geneva.

8) Holmér I (1984) Required clothing insulation (IREQ) as an analytical index of cold stress. Ashrae Trans 90, 1116-28.

9) Rintamäki H, Mäkinen T, Rissanen S, Oksa J (2002) Body heat balance and physical performance in cold. Report 200223, 31. Oulu Regional Institute of Occupational Health, Oulu (in Finnish).

10) Rintamäki H, Rissanen S, Mäkinen T, Peitso A (2004) Finger temperatures during military field training at $0--29^{\circ} \mathrm{C}$. J Thermal Biol 29, 857-60.

11) Åstrand P-O, Rodahl K (1977) Textbook of work physiology. Physiological bases of exercise, 2nd Ed., 681, McGraw-Hill Book Company, New York.

12) Rintamäki H, Mäntysaari M, Mäkinen T, Oksa J, Rissanen S, Korhonen E (1999) Effect of repeated work-exercise periods on body heat balance and physical strain. Technical report. Oulu Regional Institute of Occupational Health, Oulu (in Finnish).

13) Mäntysaari M, Rintamäki H, Mäkinen T, Oksa J, Rissanen S, Korhonen E (2002) Body heat balance during exercise in cold environment. In: Proceedings of 25th Nordic Congress on Military Medicine, Prout-Matias K (Ed.), S11, Oslo, Norway.

14) Nadel ER, Mitchell JW, Saltin B, Stolwijk JAJ (1971b) Peripheral modifications for the central drive for sweating.
J Appl Physiol 31, 828-33.

15) Rissanen S, Rintamäki H (1998) Effects of repeated exercise/ rest sessions at $-10^{\circ} \mathrm{C}$ on skin and rectal temperatures in men wearing chemical protective clothing. Eur J Appl Physiol 78, 560-4.

16) Smolander J, Louhevaara V, Korhonen O (1985) Physiological strain in work with gas protective clothing at low ambient temperature. Am Ind Hyg Assoc J 46, 720-3.

17) Atterbom HA, Mossman PB (1978) Physiological effects on work performance of vapor-barrier clothing and full-face respirator. J Occup Med 20, 45-52.

18) Kolka MA, Stephenson LA, Gonzalez RR (1994) Thermoregulation in women during uncompensable heat stress. J Therm Biol 19, 315-20.

19) McLellan TM (1996) Heat strain while wearing the current Canadian or new hot-weather French NBC protective clothing ensemble. Aviat Space Environ Med 67, 1057-62.

20) Patton JF, Bidwell TE, Murphy MM, Mello RP, Harp ME (1995) Energy cost of wearing chemical protective clothing during progressive treadmill walking. Aviat Space Environ Med 66, 238-42.

21) Nunneley SA (1989) Heat stress in protective clothing. Scand J Work Environ Health 15 (Suppl 1), 52-7.

22) Lotens WA (1983) Clothing, physical load and military performance. In: proceedings of Int Conference Biophysical and Physiological Evaluation of Protective Clothing, 26879, Lyon, France.

23) Teitlebaum A, Goldman RF (1972) Increased energy cost with multiple clothing layers. J Appl Physiol 32, 743-4. 
24) Rissanen S, Rintamäki H (1997) Thermal responses and physiological strain in men wearing impermeable and semipermeable protective clothing in the cold. Ergonomics 40,141-50.

25) Johnson AT, Grove CM, Weiss RA (1992) Respirator performance rating tables for nontemperate environments. Am Ind Hyg Assoc J 53, 548-55.

26) Bishop PA, Pieroni RE, Smith JF, Constable SH (1991) Limitations to heavy work at $21^{\circ} \mathrm{C}$ of personnel wearing the U.S. military chemical defence ensemble. Aviat Space Environ Med 62, 216-20.

27) McLellan TM (1993) Work performance at $40^{\circ} \mathrm{C}$ with Canadian Forces biological and chemical protective clothing. Aviat Space Environ Med 64, 1094-100.

28) McLellan TM, Jacobs I, Bain JB (1993) Influence of temperature and metabolic rate on work performance with Canadian Forces NBC clothing. Aviat Space Environ Med 64, 587-94.

29) Young A, O’Brien C, Sawka MN, Gonzalez RR (2000)
Physiological problems associated with wearing NBC protective clothing during cold weather. Aviat Space Environ Med 71, 184-9.

30) Rissanen S (1998) Quantification of thermal responses while wearing fully encapsulating protective clothing in warm and cold environments. In: Acta Universitatis Ouluensis D Medica 486, 71, Oulu University Press, Oulu.

31) Rissanen S, Rintamäki H, Mäkinen T, Oksa J (2002) Wearing NBC protective clothing in the cold. Report 2002-27. 35, Oulu Regional Institute of Occupational Health, Oulu (in Finnish).

32) Cortili G, Mognoni P, Saibene F (1996) Work tolerance and physiological responses to thermal environment wearing protective NBC clothing. Ergonomics 39, 620-33.

33) Imamura R, Rissanen S, Kinnunen M, Rintamäki H (1998) Manual performance in cold conditions while wearing NBC clothing. Ergonomics 41, 1421-32.

34) Lotens WA (1988) Comparison of thermal predictive models for clothed humans. Ashrae Trans 94, 1321-40. 